\title{
O PARQUE ESTADUAL DO SUMIDOURO (MG): CONFLITOS SOCIOAMBIENTAIS E O FECHAMENTO DAS PEDREIRAS
}

\author{
Amanda Figueiredo Pereira 12 \\ Maíra H. O. Costa 1 \\ Sophia P. de Faria 1 \\ Gregory N. Santos 1
}

\section{RESUMO}

O artigo trata da relação entre o Parque Estadual do Sumidouro - PES e os moradores do entorno. No passado, as principais atividades econômicas no entorno do PES eram as serrarias e pedreiras de Pedra Lagoa Santa e, atualmente, grande parte está interditada por falta de licença ambiental. O objetivo desse estudo foi analisar a existência de conflitos entre essa população e o PES, assim como o uso público do espaço do parque. A hipótese formulada é de que há uma relação negativa entre o PES e a população, na medida em que o fechamento das pedreiras ocorreu concomitantemente à implantação do parque. Foram realizadas três visitas ao PES para reconhecimento da área e coleta de dados, incluindo sete entrevistas qualitativas com moradores do entorno, moradores ligados à atividade de extração da pedra e trabalhadores do PES. A partir das entrevistas realizadas foi possível perceber que grande parte se mostrou insatisfeita com a falta de diálogo e que os entrevistados atribuem o fechamento das pedreiras à criação do PES. Constatou-se que os moradores têm dificuldade de compreender a relação entre as competências de cada órgão integrante da política ambiental, atribuindo erroneamente funções aos órgãos. A análise das entrevistas permitiu confirmar a hipótese do projeto, ou seja, há um conflito socioambiental no entorno do PES e isso tem relação com o fechamento das pedreiras. Para a minimização dos conflitos foram propostas medidas como: a criação de uma equipe para lidar com os conflitos, no cenário da Parceria Público Privada, e o desenvolvimento mais efetivo de uma educação ambiental voltada à comunidade, a fim de melhorar a relação entre o PES e os moradores do seu entorno.

Palavras chave: Conflitos socioambientais; uso público de UCs; gestão de áreas protegidas.

\begin{abstract}
The article deals about the relation between the State Park of Sumidouro - PES and the surrounding residents. In the past, the main economic activities surrounding the PES were sawmills and stone quarries Lagoa Santa and currently is largely banned by lack of environmental license. The aim of this study was to analyze the existence of conflicts between this population and the PES, as well as the public use of the park space. The formulated hypothesis is that there is a negative relationship between the PES and the population, to the extent that the closure of the quarries took place concurrently with the implementation of the park. Three visits were made to PES for recognition of the area and data collection, including seven qualitative interviews with surrounding residents, residents linked to mining activity

\footnotetext{
${ }^{1}$ Aluno (a) do curso de Ciências Socioambientais, da Universidade Federal de Minas Gerais (UFMG)

${ }^{2}$ E-mail: amanda1500@hotmail.com; Amandafigueiredo@ufmg.br
} 
stone and PES workers. From the interviews it was revealed that much of proved dissatisfied with the lack of dialogue and that the respondents attribute the closure of the quarries to the PES creation. It was found that the locals have difficulty understanding the relationship between the competences of each body member of the environmental policy, erroneously assigning roles to organs. Analysis of the interviews confirmed the hypothesis of the project, ie, there is a socio-environmental conflict surrounding the PES and this is related to the closure of the quarries. To minimize the conflicts have proposed measures such as the creation of a team to deal with conflicts in the Public Private Partnership scenario, and the most effective development of environmental education geared to the community in order to improve the relationship between the PES and the residents of your surroundings.

Keywords: Environmental conflicts; public use of protected areas; management of protected areas.

\section{INTRODUÇÃO}

A Constituição da República Federativa do Brasil (BRASIL, 1988) assegura para todos os cidadãos, por meio de seu artigo 225, o direito de viverem em um ambiente ecologicamente equilibrado, que garanta a sadia qualidade de vida e, junto a esse direito, destaca o dever do Poder Público e da Sociedade Civil de preservá-lo para que seja possível o desfrute de gerações futuras. A lei também destaca a importância em determinar áreas específicas e destiná-las à manutenção dos processos e complexos ecológicos existentes nos diversos ecossistemas do país.

Dentro deste contexto, como uma das formas de fazer valer o direito a um ambiente equilibrado e proporcionar a conservação do meio ambiente, foi instituído em 2000, pela Lei $\mathrm{n}^{\circ}$ 9.985, o Sistema Nacional de Unidades de Conservação da Natureza - SNUC, que dispõe sobre normas para a criação, implantação e administração das Unidades de Conservação UC. As unidades de conservação (UC) são importantes para garantir a proteção de espécies ameaçadas e para evitar a vulnerabilidade das que ainda não se encontram dentro desse grupo, além da preservação das paisagens tidas como raras e de notável beleza cênica e das modalidades destinadas ao extrativismo e a preservação de características culturais.

O Parque Estadual do Sumidouro (PES), objeto de estudo deste artigo, foi criado em janeiro de 1980, e está localizado nos municípios mineiros de Lagoa Santa e Pedro Leopoldo. O PES se insere dentro dos limites da APA Carste de Lagoa Santa (Figura 1) e destaca-se pela importância de seu patrimônio paleontológico, arqueológico e espeleológico. A região abrangida pelo parque possui a presença de rochas carbonáticas, o que confere ao parque a existência de surgências, sumidouros e cavidades, havendo nessas últimas a presença de variados espeleotemas e de fauna cavernícola. O parque engloba a gruta da Lapinha, com 511 metros de extensão e 40 metros de profundidade, sendo considerada uma das 7 maravilhas da estrada real. A flora da UC é bastante diversificada, contanto com espécies de Cerrado e Mata Atlântica (IEF). 


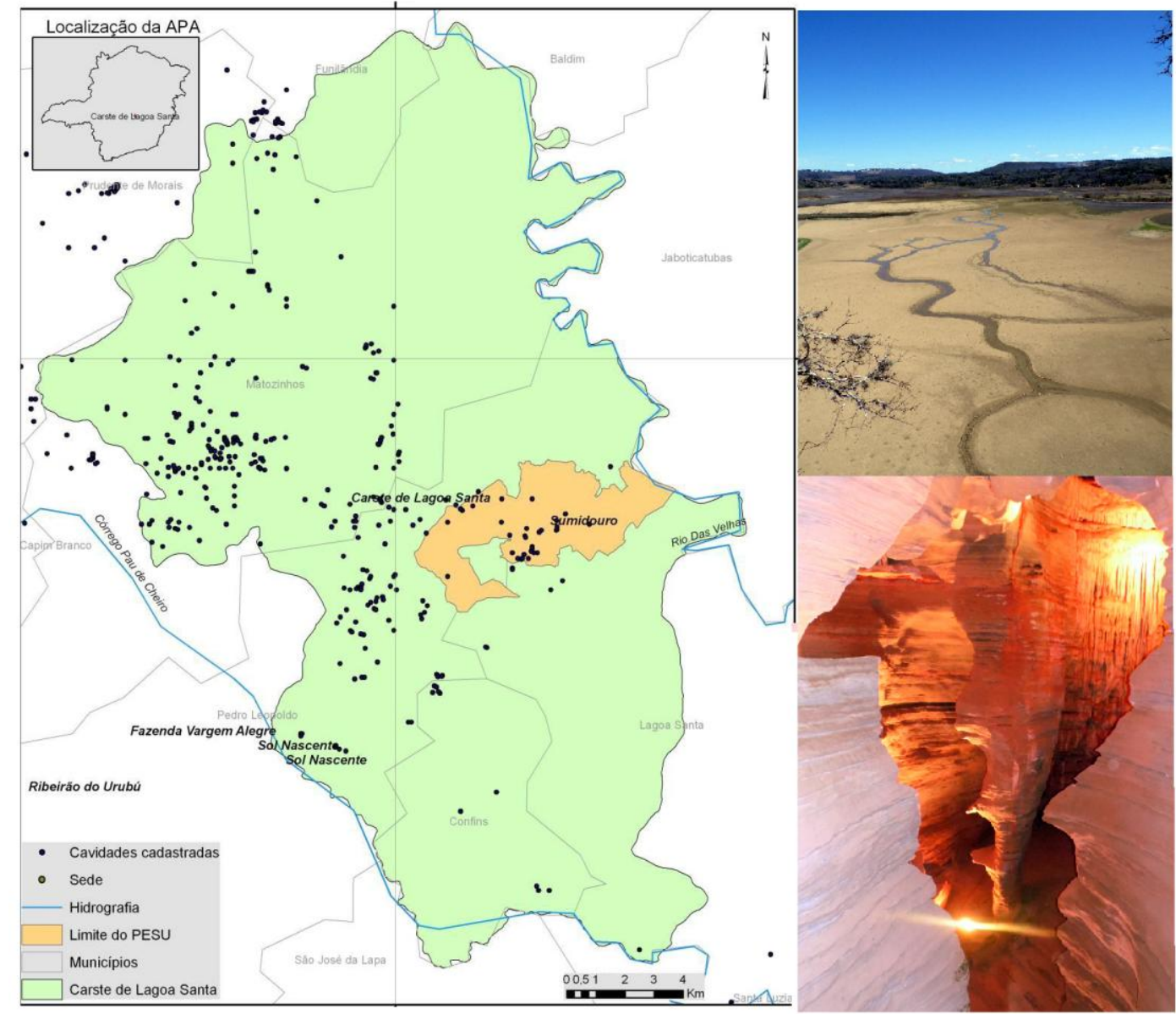

Figura 1- Mapa dos Limites do PES e da APA. À direita a Lagoa do Sumidouro durante a seca e a gruta da Lapinha. Fonte: Mapa do Guano Speleo UFMG, foto dos autores.

\section{Criação de Parques no Brasil: inspiração no modelo de conservação Norte Americano}

O primeiro parque do mundo foi criado nos Estados Unidos em 1872, denominado Yellowstone National Park. A criação dos primeiros parques tinha como objetivo preservar "ilhas de natureza" tidas como intocadas, selvagens, que apresentassem rara beleza cênica, servindo como refúgio para a sociedade industrial. Essa espécie de paraíso perdido deveria ser protegida porque o homem seria naturalmente destruidor e buscaria nesses espaços um conforto momentâneo para fugir do estresse das cidades. A natureza selvagem não tinha, inicialmente, um valor em si, servindo apenas como refúgio para a sociedade urbanoindustrial, em uma visão marcadamente antropocêntrica (DIEGUES, 2001).

Esse modelo de conservação por meio da criação de parques foi exportado para o Terceiro Mundo, com uma realidade significativamente diferente da norte americana, e passou a ser uma das principais estratégias de conservação desses países. A criação de parques no Brasil foi, em muitos casos, feita com a desconsideração das populações inseridas nesses lugares, como se estas fossem, assim como pensavam os norte americanos, essencialmente destruidores da natureza. 
Raramente as populações são consultadas sobre a criação das unidades de conservação, e também, raramente, são convidadas a participar efetivamente da gestão dessas áreas. A expulsão dos moradores tem, em muitos casos, consequências perversas como o aumento da degradação em função da falta de fiscalização das áreas - o que abre margem para a instalação de indústrias madeireiras e empreendimentos degradantes - além da degradação pela própria comunidade, que em função de um sentimento de revolta "retiram ilegalmente meios de subsistência dessas áreas protegidas, tidas como recursos perdidos pelas comunidades locais" (DIEGUES, 2001, p. 13).

Tomando como luz a criação impositiva de UC que foram e continuam sendo feitas no país, torna-se necessário averiguar como ocorreu o processo de implantação do PES e como tem sido a relação atual de diálogo entre o parque e a comunidade do entorno, assim como o uso público que é feito pela comunidade.

\section{OBJETIVOS}

O objetivo geral da pesquisa é analisar se há um conflito entre moradores do entorno e o PES, e se houver conflito, investigar se há uma influência das pedreiras nas motivações que acirram e geram o conflito, avaliando se há a apropriação do espaço do parque por meio da comunidade. Por meio das entrevistas, objetiva-se entender as posições dos atores envolvidos nos conflitos a fim de buscar possíveis soluções para este. Buscou-se também analisar a estrutura geológica da pedreira, a forma como a extração e o beneficiamento são feitos, compreendendo assim os possíveis impactos ambientais causados por estes.

\section{MATERIAL E MÉTODOS}

Para a realização da pesquisa estudou-se a área que apresenta o conflito que envolve o PES e a comunidade no entorno do município de Lagoa Santa. O reconhecimento da área do Parque foi feito por meio de visitas técnicas com a orientação dos guias do parque, o que ajudou a entender como a demarcação da UC foi realizada e quais as implicações na comunidade.

As entrevistas possibilitaram avaliar as implicações para a comunidade em função da implantação do parque. Foram realizadas 7 entrevistas em caráter qualitativo, envolvendo os guias e o gerente do parque, além de alguns moradores da região da Quinta do Sumidouro.

Para a realização da pesquisa, foram elaborados roteiros semi-estruturados para possibilitar a melhor interação com os entrevistados, além de atender aos objetivos de investigação da equipe. Nas entrevistas semi-estruturadas o pesquisador deve seguir um conjunto de questões previamente definidas, mas ele o faz em um contexto muito semelhante ao de uma conversa informal (BONI; QUARESMA, 2005)

Ressaltamos que as entrevistas foram realizadas geralmente por todos os membros do grupo e quando ficava inviável a presença de todos, ao menos dois integrantes estavam presentes. Os autores acreditam que a entrevista realizada em grupo auxilia e melhora a percepção sobre como os entrevistados se comportam, pois diante das falas analisadas 
percebe-se que há distinção na forma como os discursos são proferidos. Para coleta dos dados, foram utilizados gravadores de celular e do notebook, mediante o consentimento dos entrevistados.

Além das entrevistas foi realizada uma visita a uma das pedreiras para a análise visual dos impactos ambientais gerados pela extração de bens minerais. A aparência geológica da parte exposta da pedreira junto ao estudo de pesquisas já realizadas sobre as rochas, permitiu ao grupo discutir a importância econômica que a extração da Pedra de Lagoa Santa, de base calcária, tem para a população atingida pelo fechamento das pedreiras, que ocorreu em paralelo a criação do PES.

\section{RESULTADOS}

\section{Caracterização das Pedreiras: A Pedra Lagoa Santa}

Nas pedreiras existentes no entorno do PES é extraído o calcário dolomítico, popularmente conhecido como Pedra Lagoa Santa, uma rocha ornamental com boas perspectivas comerciais. A rocha é extraída em pedreiras localizadas nos municípios de Pedro Leopoldo e Funilândia.

As pedras ornamentais têm um importante papel na construção civil e são definidas pela ABNT (1992) como um material rochoso natural, submetido a diferentes graus de aperfeiçoamento e utilizado para exercer uma função estética. Na construção civil, podem ser utilizadas como revestimentos internos e externos de paredes, pisos, pilares, tampões, pés de mesas (BARBOSA, 2008 apud ABRIROCHAS, 2007).

No que se refere à sua formação geológica, a Pedra Lagoa Santa possui características dos mármores e propriedades físicas e mecânicas das ardósias. A composição da pedra é rica em carbonato de cálcio, o que a aproxima dos mármores. Semelhante à ardósia, a pedra Lagoa Santa apresenta planos preferenciais de clivagem - que pode ser definido como a tendência a partir-se segundo superfícies planas - o que facilita o desdobramento da rocha, devido aos pontos naturais de partição. A constituição natural da pedra dispensa, portanto, a utilização de teares e talha blocos para realizar o desdobramento da rocha, que é facilmente feito sem a utilização dessas ferramentas (BARBOSA, 2008).

As pedreiras são a céu aberto, normalmente com grande desenvolvimento horizontal e vertical. Após a extração dos blocos, estes sofrem o processo de beneficiamento, que é constituído do corte no tamanho exigido pelo mercado e o desdobramento em chapas. Grande parte das serrarias se concentra no distrito de Fidalgo, pertencente a Pedro Leopoldo, mas foram observadas serrarias também na Quinta do Sumidouro.

A extração da pedra Lagoa Santa está sujeita ao licenciamento ambiental, assim como o processo de beneficiamento da rocha nas serrarias. Por se localizarem dentro da APA Carste Lagoa Santa, as pedreiras estão ainda sujeitas à anuência do Instituto de Conservação Chico Mendes (ICMbio), órgão gestor da APA. 
Grande parte das pedreiras e serrarias está situada dentro da Zona de Proteção do Patrimônio Cultural (ZPPC) da APA Carste Lagoa Santa, uma entre as seis zonas estabelecidas no Zoneamento Ambiental da APA. A ZPPC visa proteger e promover conjunto paisagístico e a cultura regional, além de proteger o ecossistema úmido e a biota remanescentes em ambiente lacustre, em especial a avifauna associada à lagoa do Sumidouro. $\mathrm{Na}$ área da ZPPC estão inseridos os distritos de Fidalgo e da Quinta do Sumidouro, e entre os conflitos de uso citados na área estão a extração e beneficiamento de Pedra Lagoa Santa. A diretriz refere à ZPPC incentiva a criação de um distrito industrial para receber as serrarias, onde é feito o beneficiamento da rocha. Dentro da zona, por mais que seja citado como um conflito de uso, a extração da rocha é citado como um uso tolerado, desde que devidamente licenciado e que os produtores estejam vinculados à programas de extensão ambiental, destinado à redução dos impactos da atividade, melhoria tecnológica e redução de perdas (IBAMA, 1998).

Foi observado, no entanto, que grande parte das pedreiras e serrarias não possuem licença ambiental, e parte delas ainda funciona de maneira clandestina. Por meio da comparação de dados de GPS obtidos em campo e as bases de processos do DNPM (Departamento Nacional de Produção Mineral), percebe-se que existem diversos requerimentos de lavra e pesquisa, mas poucos processos têm evoluído efetivamente no sentido de obter o licenciamento ambiental.

Dentre os possíveis impactos ambientais gerados pela extração e beneficiamento das rochas estão a formação de lama devido aos finos gerados no processo de beneficiamento da rocha, o ruído sonoro causado pelas máquinas utilizadas no corte dos blocos, acumulação de rejeitos da rocha nas vias públicas e carreamento dos finos gerados nas lavras pelo curso d'água. Nas serrarias presentes em Fidalgo, de acordo com estudos realizados em 2011, parte dos finos estaria sendo lançado sem tratamento prévio no Córrego da Bucha, afluente da Lagoa do Sumidouro, causando o assoreamento da lagoa (GARCIA, 2011).

\section{Análise das entrevistas}

Para facilitar o processo de análise das entrevistas, foram estabelecidos alguns temas preponderantes abordados durante a pesquisa. Por meio da definição desses temas, é possível perceber com mais clareza as divergências e semelhanças entre as posições dos autores.

\section{O fechamento pedreiras na visão dos entrevistados}

O fechamento das pedreiras foi atribuído, pela maioria dos entrevistados, como estando diretamente relacionado à criação e implantação do PES. Na época em que as pedreiras ainda eram utilizadas para a extração da Pedra Lagoa Santa, grande parte da população estabelecia vínculo econômico com essa atividade - os que não trabalhavam dependiam da renda gerada a partir das relações familiares, principalmente.

Como os locais de extração não eram legalmente autorizados, foram todos interditados e os trabalhadores, consequentemente, impedidos de dar continuidade às atividades. A 
interdição ocorreu paralelamente à implantação do PES, causando equívocos em relação às razões do fechamento por parte da população. Com isso os moradores se sentem extremamente enganados pelo parque e tomam para si o argumento de que ele foi o principal responsável para o fechamento das pedreiras. Os trechos a seguir ilustram o sentimento da população sobre esse tópico:

"Se você for conversar com a diretoria do parque eles vão falar que não tem nada haver com isso. Mas se você for mais afundo na papelada, com o negócio do governo, o parque tem muita coisa a ver". (14 set de 2013).

"Foi o parque. Depois que o parque veio pra aqui as serrarias fecharam." (14 set de 2013).

\section{Impactos do fechamento das pedreiras para os entrevistados}

Com base nas entrevistas, a opinião dos entrevistados quanto aos impactos trazidos pelo PES à localidade, nota-se que as ações desenvolvidas pela UC não atingem as expectativas de parte dos moradores. Foi possível perceber especialmente um descontentamento em relação à falta de desenvolvimento econômico da região e a atribuição de culpa ao parque por esse fato. A seguinte fala retrata bem isso: "Quando falaram que o parque ia vir pra cá falaram que o parque ia ser sustentável, que ia trazer beneficio pros moradores, hoje você pode perguntar qualquer pessoa o que o parque trouxe de beneficiamento. Nada, só piora.” (14 set de 2013).

Além disso, entrevistados alegaram que houve promessas de aumento de renda por influência de maior número de turistas e realização de trabalhos artesanais para comercialização.

\section{Percepção quanto à diferenciação dos atores envolvidos no conflito}

Quanto à diferenciação de atores envolvidos, houve certo equilíbrio entre os entrevistados. Houve os que não souberam, realmente, conectar órgãos públicos à situação de conflito, responsabilizando o parque pela má qualidade da água fornecida pelo sistema de abastecimento local por exemplo.

Em contrapartida, outros entrevistados souberam organizar as ações de órgãos públicos ao contexto, estes, talvez, possuíam maior conhecimento quanto a essas questões de competência dos órgãos, por participarem mais ativamente de movimentos relacionados às associações dos bairros próximos à UC.

\section{A apropriação da comunidade da área do parque e o uso público}

Os entrevistados afirmaram não utilizar e visitar a área do parque, e os vínculos que se estabelecem entre a comunidade e o PES são ligados apenas à relação de trabalho, visto que a maioria dos funcionários pertence à comunidade. Foi percebido um descontentamento se refere à restrição quanto ao uso do espaço do parque pela população, e um dos entrevistados afirmou que "muitos iam à lagoa pra pescar, pra acampar (...) Deve ter mais de três anos que 
eu não vou à Lagoa porque está fechada. Lá era o único lazer que as pessoas tinham.” (26 nov. 2013). Outro entrevistado afirmou que "o parque tirou a liberdade do povo" (14 set de 2013).

Em entrevista realizada com os guias do parque, foram apresentados alguns dos trabalhos realizados no PES que são abertos à comunidade, como palestras e atividades de educação ambiental com escolas da região. As informações relativas ao parque são divulgadas em um jornal, disponibilizado dentro do parque e por meio das redes sociais e site do parque. É importante destacar que essas formas de divulgação nem sempre atingem a comunidade local, especialmente as que ocorrem por meio da internet, devido à falta de residências que possuem o serviço na região. Segundo a guia, o que é feito dentro do parque não é valorizado, mas ao mesmo tempo ela reconhece que a divulgação nem sempre é bem feita, sendo um ponto a ser trabalhado dentro do parque.

Segundo o que foi informado pelo gerente do PES existem projetos que devem ser implementados que buscarão uma maior integração com a comunidade como, por exemplo, o projeto Trilha da Saúde, que será um convite para que as academias livres de Lagoa Santa façam trilhas e conheçam o parque, "pra que não só as comunidades do entorno, mas o pessoal também de Lagoa Santa conheça e valorize o Parque (29 out de 2013)".

Um dos pontos positivos em relação à integração com a comunidade é o número de funcionários contratados: 50 de um total de 67 pertencem à comunidade. Os funcionários revelaram, no entanto, que há uma certa retaliação aos membros da comunidade que passam a trabalhar no parque, em função da oposição de grande parte da comunidade em relação ao PES.

\section{A relação entre o PES, o gerente do parque e a comunidade do entorno}

A imagem que a maioria dos entrevistados possui do gerente é bastante negativa, afirmando que ele desrespeita a comunidade e que não há uma relação entre o gerente a população. Pela grande aversão que os moradores têm em relação ao gerente, possivelmente grande parte dos problemas associados ao parque se devem a essa relação conflituosa, e talvez menos problemas em relação ao parque fossem apontados pela comunidade caso houvesse uma relação mais harmônica.

Uma das entrevistadas, moradora da Quinta e ligada às pedreiras e serrarias, diz que sente uma pequena perseguição do gerente com a comunidade aqui. Afirma também que "muita gente já tentou mesmo matar esse gerente, muita gente tem ódio dele mesmo, porque a pessoa que ta num cargo superior ela quer diminuir as pessoas, e quando acontece isso as pessoas ficam indignadas" (14 set de 2013).

Outra entrevistada, integrante da associação da Quinta, disse que o gerente não tem nenhuma ligação com a comunidade, e que só procura a associação quando precisa. No fim da entrevista concedida, a moradora disse: "Mostra a pesquisa pro senhor gerente, e fala com ele que aprenda a ser mais humano, que não é assim que a gente trata uma comunidade humilde. 
Não é assim que ele vai conseguir o objetivo dele, pensando só nele. Primeiramente ele tinha que ter pensado na comunidade" (5 de out de 2013).

Pela entrevista feita com o gerente, uma das causas apontadas por ele para tamanha revolta é a implantação de um discurso político na comunidade, que acaba incitando a população a se posicionar contra ao parque, criando-se assim um forte dualismo: os que são contra e os que são a favor do parque. Na entrevista, o gerente disse que "as pessoas querem ganhar, e as pessoas são imediatistas (29 de out de 2013)", e que assim não estaria sendo dado o tempo que o parque precisa para se adaptar.

Outros motivos também foram citados como geradores da aversão da comunidade em relação ao parque, como a não construção do distrito industrial e a impossibilidade do parque de oferecer emprego a todos os moradores.

Segundo o gerente, na implementação do parque foram feitas "reuniões, palestras, buscou-se convidar as pessoas da comunidade pra integrar o conselho. Nós tivemos um primeiro conselho, de dois anos, com uma participação maior das associações locais. Hoje, as associações locais pela própria inoperância, foram convidadas, mas não participaram do processo de renovação do conselho (29 out de 2013)".

\section{CONCLUSÕES E PROPOSIÇÕES}

São muitos e inegáveis os desafios para a busca de uma relação mais harmônica com a população. Na entrevista concedida, o gerente afirmou que o parque é "um lugar que tem potencial pra ser patrimônio da humanidade, mas eu tenho que ficar aqui, comendo o pão que o diabo amassou para mostrar para as pessoas que elas são parte desse tesouro (29 out de 2013)". O parque possui um enorme e inegável potencial turístico devido às características espeleológicas e paleontológicas, mas o uso público que é feito do espaço não é compartilhado por parte da população que o cerca e é necessário que o uso do espaço seja ampliado nas duas frentes: pela comunidade do entorno e pelos demais visitantes.

Por maiores que sejam os desafios, é também inegável que ainda há muito que ser feito. Os projetos do parque ainda estão voltados muito para o futuro e pouco tem sido feito no presente para alcançar essa relação mais amigável com a comunidade do entorno. É preciso buscar de forma mais intensa melhorar essa interação, estabelecendo esta como uma das prioridades do parque, até mesmo por acabar interferindo na própria conservação do espaço.

A partir das questões apresentadas, conclui-se que o PES e a comunidade influenciada por ele apresentam boas intenções em busca de uma cooperação mútua. No entanto, devido à falta de diálogo entre eles, a dificuldade para amenizar o conflito aumenta e a comunidade claramente não se apropria do espaço da UC, sendo o uso público do espaço feito majoritariamente por pessoas externas à comunidade. Soma-se a isto o desalinho no que se refere ao entendimento por parte da população local sobre quais os órgãos ambientais são de fato responsáveis pela implantação do parque e o fechamento das pedreiras.

As entrevistas com os moradores mostram que muitos culpam de maneira exclusiva o PES pela diminuição de renda ocorrida com a perda do trabalho exercido nas pedreiras. 
Porém, o parque, assim como sua gestão, não foi o responsável direto por tal feito. A hipótese mais viável é que, com a demarcação da UC, a presença dos órgãos fiscalizadores tornou-se maior na região. Sendo assim, irregularidades como as pedreiras clandestinas que funcionavam sem licenciamento ambiental foram diagnosticadas e barradas em continuar com suas atividades.

A associação entre criação do Parque e o fim das pedreiras como fonte de renda foi feita pela população, causando grande aversão à área de conservação. É inegável que o fechamento das pedreiras desestabilizou o modo de vida da região estudada. A discrepância entre os salários daqueles que tinham a pedreira como fonte de renda alterou o ciclo econômico, prova disto são os relatos dos moradores que alegaram que a renda obtida com o trabalho nas pedreiras passou de três mil reais para aproximadamente um salário mínimo.

Diante desse cenário propõem-se as seguintes medidas:

\section{A criação da parceria público privada e suas oportunidades}

O governo de Minas Gerais lançou recentemente um edital que prevê a formação de uma Parceria Público Privada (PPP), que levaria à concessão administrativa para a exploração da gestão de áreas das unidades de conservação do Parque Estadual do Sumidouro, Monumento Natural Estadual Gruta Rei do Mato e Monumento Natural Estadual Peter Lund. Se concluído, esse será o primeiro projeto PPP para conservação de áreas protegidas do país.

O prazo inicial da concessão é de 30 anos, prorrogáveis por forma de lei ou pelo edital. Se o projeto for concluído, os recursos disponíveis para a gestão do parque aumentarão de forma significativa e será possível pensar em planos e ações de gestão mais abrangentes. $\mathrm{O}$ Plano de Manejo do parque prevê que os recursos para os projetos são de 25 milhões a cada 5 anos. No cenário de PPP, o investimento mínimo do projeto, segundo o edital, é de cerca de 300 milhões.

Nesse cenário de concretização da parceria, é necessário que haja por parte das prefeituras de Lagoa Santa e Pedro Leopoldo, projetos de capacitação da comunidade, para que esta possa aproveitar da melhor forma possível a grande quantidade de recursos que passará a ser destinada para a região. Mais importante que essa capacitação, é a criação de uma equipe especial para lidar com os conflitos e a relação com a comunidade, caso se efetive a parceria. Com os recursos atuais do parque a criação de uma equipe como esta possivelmente seria inviável, mas com o aumento dos recursos em função da parceria, essa criação seria viabilizada.

\section{Criação de espaços de diálogo}

Em toda organização, se faz necessário um sistema de gestão para que seja possível obter melhor controle das atividades desenvolvidas. Devem ser levados em consideração diversos fatores que contribuam para o bom ou mau funcionamento das UCs, e um desses fatores é a relação harmônica com a comunidade do entorno e a apropriação desta do espaço do parque. A fim de possibilitar esses objetivos, são sugeridos sistemas de Conselho 
Participativo (consultivos e deliberativos) e Gestão Participativa que visam integrar a sociedade civil local às decisões tomadas referentes à área física que influenciam e sofrem influência, com objetivo de descentralizar o poder administrativo das áreas destinadas à conservação ou preservação.

Quando a sociedade se sente parte atuante no planejamento dos processos administrativos de sua localidade, o desejo de cooperação para a conservação das boas relações se torna mais intenso. Adotando esses sistemas de conselho e gestão participativos, é bem provável que se obtenha relações mais harmoniosas entre a população local e as respectivas áreas protegidas.

\section{Educação Ambiental}

É necessário que se construa, conjuntamente com a população, as razões pelas quais o patrimônio protegido pelo parque deve ser preservado. É preciso que a comunidade seja convidada a pensar nas belezas e na importância da preservação da área, a fim de que se crie uma identidade entre a população e o parque e o desejo de manter a região conservada. Espera-se que com uma maior dedicação a atividades de educação ambiental, aumente o uso público do PES por parte da comunidade.

\section{Investimento por parte do poder público}

Como se pôde observar, os entrevistados sentem falta de espaços destinados à recreação, que já é escassa na região e diminuiu ainda mais com a criação do parque e as restrições de uso do espaço. As atividades de lazer, asseguradas pela constituição federal do Brasil, são de extrema importância para a manutenção do bem-estar físico. Assim, a implantação de áreas de recreação, destinadas ao uso pela população, devem ser analisadas pelo poder público a fim de que associada às demais propostas apresentadas, seja melhorada a relação parque-comunidade

\section{REFERÊNCIAS BIBLIOGRÁFICAS}

BRASIL. Artigo 225. Nov. 2012. Disponível em: <http://www.dji.com.br/constituicao_federal/cf225.htm>. Acesso em: 2 nov. 2013.

BRASIL. Lei $\mathbf{N}^{\mathbf{9}} \mathbf{9 . 9 8 5}$, de 18 de julho de 2000. Nov. 2012. Disponível em: <http://www.planalto.gov.br/ccivil_03/leis/L9985.htm>. Acesso em: 2 nov. 2013.

BONI, V.; QUARESMA,S.J. Aprendendo a entrevistar: como fazer entrevistas em Ciências Sociais. Revista TESE, Santa Catarina, v.2, n.1,p.68-80, 2005

GARCIA, Valeria Campos. Propostas de medidas de controle ambiental para a revitalização da área urbana do distrito de Fidalgo em Pedro Leopoldo - MG. Dissertação (mestrado) - UFOP. Ouro Preto, 2011.

IBAMA. Zoneamento Ambiental da APA Carste de Lagoa Santa. Belo Horizonte, 1998. $61 \mathrm{p}$. 
IBASE. Gestão Participativa em Unidades de Conservação. 2006. Disponível em:<http://www.ibase.br/userimages/ap_ibase_gestao_01c.pdf>. Acesso em: 13 nov. 2013.

IEF. Área de Proteção Ambiental - APA. 2013. Disponível em: < http://www.ief.mg.gov.br/areas-protegidas/areas-protegidas-estaduais/117>. Acesso em: 29 de novembro de 2013.

MACEDO, F. F.; LIPARINI, A.; MUNIZ, F.G. Atualização dos registros de cavidades cadastradas para o Parque Estadual do Sumidouro (Lagoa Santa/Pedro Leopoldo MG) e levantamento de novas ocorrências de cavernas para a região do parque e o seu entorno. 2011. Disponível em <http://www.sbe.com.br/anais31cbe/31cbe_581-592.pdf> Acesso em 27 de novembro de 2013.

MINAS GERAIS. Edital da PPP Rota Lund, 2013. Disponível em: <http://www.ppp.mg.gov.br/projetos-ppp/projetos-em-elaboracao/rota-lund-

1/Edital\%20e\%20Anexos.zip/view>. acesso em $06 \mathrm{dez} 2013$.

MMA. Gestão Participativa do SNUC. 2004. Disponível em:< http://www.mma.gov.br/estruturas/sbf2008_dap/_publicacao/149_publicacao1612201010025 3.pdf $>$. Acesso em: $13 \mathrm{dez} .2012$.

ORTH, Dora Maria; CUNHA, Rita Dione Cunha. Praças e áreas de lazer como ambiente construído influenciando na qualidade de vida urbana. In: ENTAC 2000, Salvador, BA. 2000. $\quad$ v. $01, \quad$ p. 474-475. Disponível em: <http://www.grupoge.ufsc.br/publica/artigos/pracas.pdf>. Acesso em: 29 nov. 2013.

SAMPAIO, Jarba Lima Dias. Inventário digital da APA (Área de Proteção Ambiental) Carste Lagoa Santa e algumas implicações. 2010. 195 f. Tese (Doutorado) - Pontifícia Universidade Católica de Minas Gerais, Programa de Pós Graduação em Tratamento da Informação Espacial.

VIVACQUA, Melissa. Conflitos socioambientais em Unidades de Conservação. In: Política \& Sociedade, N. 7, outubro de 2005. 